\title{
STUDI RAMBATAN PANAS PADA PEMODELAN PIROLISATOR KAPASITAS 20 LITER MENGGUNAKAN COMPUTATIONAL FLUID DYNAMICS
}

\author{
Fajar Dwi Saputro, Imam Syafa'at* dan Tabah Priangkoso \\ Jurusan Teknik Mesin, Fakultas Teknik, Universitas Wahid Hasyim \\ Jl. Menoreh Tengah X/22, Sampangan, Semarang 50236. \\ "Email: imamsyafaat@unwahas.ac.id
}

\begin{abstract}
Abstrak
Pirolisator merupakan alat untuk menghasilkan asam cair yang berasal dari pemanasan bahan mentah berupa tempurung kelapa dalam suhu yang tinggi yang dinamakan pirolisis, dalam prosesnya reaktor yang berisi bahan mentah tersebut akan ditutup kemudian dipanaskan sehingga terjadi pemanasan di dalam reaktor yang akan memicu keluarnya asap hasil dari pemanasan arang tersebut, tujuan dati penelitian ini yakni mengetahui jenis rambatan panas yang terjadi dan bagaimana rambatan panas terjadi pada pirolisator, dengan menggunakan metode simulasi analitis menggunakan software SolidWorks. Pada simulasi, hasil yang di dapat yakni perubahan temperatur selama proses, dengan input temperatur 400 ${ }^{\circ} \mathrm{C}$ dan menghasilkan sebaran suhu pada dasar tabung $265,35^{\circ} \mathrm{C}$, pada tengah tabung 99,95 ${ }^{\circ} \mathrm{C}$, pada tutup tabung $91,93{ }^{\circ} \mathrm{C}$ dan pada ujung pipa uap adalah $59,89{ }^{\circ} \mathrm{C}$. Menghasilkan kesimpulan bahwa temperatur yang didapat terjadi selisih antara hasil simulasi dengan hasil pengujian hal ini terjadi karena pada simulasi tidak menggunakan beban material tambahan, sedangkan pada saat pengujian terdapat material tambahan.
\end{abstract}

Kata kunci: Pirolisator, Tempurung kelapa, Rambatan panas, Temperatur, Konveksi

\section{PENDAHULUAN}

Pirolisator merupakan alat yang digunakan dalam pembuatan asap cair yang memanfaatkan limbah dari tempurung kelapa untuk di panaskan dalam ruang tertutup sehingga asap yang dihasilkan kemudian akan didinginkan menjadi asap cair. Gabe (2015), dalam penelitiannya pirolisis merupakan proses degradasi termal dari suatu bahan atau material tanpa melibatkan oksigen. Pada tingkatannya pirolisis dibagi pada dua proses yaitu proses primer dan proses sekunder, pirolisa primer adalah pirolisis yang terjadi pada bahan baku, sedangkan pirolisa sekunder adalah pirolisis yang terjadi pada partikel dan gas/uap hasil pirolisis primer. pirolisis konvensional (pirolisis lambat) di bawah tingkat pemanasan rendah dengan hasil berupa padat, cair, dan produk gas dalam porsi yang signifikan, proses ini digunakan untuk menghasilkan arang.

Dalam penelitiannya Demirbas (2009), mengatakan pirolisis cepat dikaitkan dengan tar, pada suhu rendah 850-1250 K dan atau gas pada suhu tinggi 1050-1300 K. Saat ini teknologi ini disukai karena dapat beroperasi pada suhu tinggi dan memerlukan waktu yang singkat. Pirolisis cepat lebih akurat didefinisikan sebagai termolisis dimana suatu proses materi seperti biomassa, dipanaskan dengan cepat sampai suhu yang tinggi tanpa adanya oksigen. Pada penelitian yang telah dilakukan Paris (2005), mengatakan bahwa pirolisis merupakan proses pengarangan tidak sempurna menggunakan suhu tinggi pada bahan-bahan yang mengandung karbon. Pada umumnya reaktor pirolisis dibuat menggunakan baja, sehingga bahan yang akan di pirolisis tidak melakukan kontak langsung dengan oksigen.

Pada umumnya proses pirolisis berlangsung pada suhu diatas $300{ }^{\circ} \mathrm{C}$ dalam waktu 4-7 jam. Namun hal ini tergantung pada bahan baku dan cara pembuatannya (Demirbas, 2005). Melihat hasil penelitian terdahulu perlu dilakukan penelitian kembali dengan variasi temperatur yang berbeda untuk menganalisis distribusi temperatur secara simulasi menggunakan software Solidworks untuk mengetahui pengaruh suhu input pada simulasi terhadap laju rambatan panas pada alat pirolisator agar dapat diketahui perbandingan hasil simulasi dengan hasil pengujian menggunakan metode simulasi elemen hingga dan analitis.

\section{DASAR TEORI \\ Perpindahan Panas}

Menurut Holman (1995), perpindahan kalor merupakan ilmu yang berguna untuk 
memprediksi laju perpindahan energi yang berpindah antar material sebagai akibat perbedaan temperatur.

\section{Konveksi}

Perpindahan panas konveksi menurut Kreith (1994), Yaitu perpindahan panas yang terjadi antara permukaan padat dengan fluida yang mengalir di sekitarnya, dengan menggunakan media penghantar berupa fluida (cairan/gas). Menurut Holman (1995), Secara umum besaran kalor dalam konveksi dapat dihitung melalui Persamaan (1).

$$
q=h A\left(T_{s}-T_{\infty}\right)
$$

Dimana :

$Q=$ Kalor yang dipindahkan (watt)

$H=$ Koefisien perpindahan panas konveksi (watt $/ \mathrm{m}^{2} \mathrm{~K}$ )

$A=$ Luas permukaan dinding $\left(\mathrm{m}^{2}\right)$

$\left(T_{s}-T_{\infty}\right) \quad=$ Perbedaan suhu dinding dengan suhu fluida $(\mathrm{K})$

Perhitungan distribusi suhu pada pelat rata vertikal maka dapat diselesaikan dengan menggunakan Persamaan (2).

$$
\frac{T-T \infty}{T W-T \infty}=\left(1-\frac{y}{\delta}\right)^{2}
$$

$$
\begin{array}{ll}
\mathrm{T} & =\text { Distribusi suhu }(\mathrm{C}) \\
\mathrm{T} \infty & =\text { Suhu pemanasan bahan }(\mathrm{C}) \\
\mathrm{T}_{\mathrm{w}} & =\text { Suhu dinding }(\mathrm{C}) \\
\mathrm{y} & =\text { Jarak per titik }(\mathrm{mm}) \\
\mathrm{L} & =\text { Jarak keseluruhan } \quad(\mathrm{mm})
\end{array}
$$

(Holman, 1995)

\section{Solidworks}

Solidwork merupakan software yang digunakan untuk membuat desain produk dari yang sederhana sampai yang kompleks, dalam pembuatan model 3D Solidwork menyediakan feature-based, parametric solid modeling dan juga simulasi (Matsson, 2013).

\section{METODOLOGI}

\section{Alat dan Bahan}

Alat yang digunakan dalam penelitian ini adalah pirolisator yang mempunyai fungsi untuk proses pirolisis tempurung kelapa sehingga menghasilkan asap dari proses pemasakan yang diproses menjadi asap cair dan terdapat termokopel pada tutup tabung reaktor untuk mengetahui temperatur didalam tabung reaktor pirolisator dan terdapat dua lubang yang berada di sisi dan atas pirolisator yang berfungsi untuk memasukkan dan mengeluarkan tempurung kelapa, bagian-bagian alat ini terbuat dari AISI 304 yang merupakan material logam baja stainless tahan karat dengan kekerasan tinggi yang mempunyai konduktivitas termal $16,2 \mathrm{~W} / \mathrm{m}-\mathrm{K}$ pada $0-100$ ${ }^{\circ} \mathrm{C}$, dan $21,5 \mathrm{~W} / \mathrm{m}{ }^{\circ} \mathrm{C}$ pada $500{ }^{\circ} \mathrm{C}$, serta mempunyai komposisi kimia dengan kandungan $\mathrm{Fe} 71 \%$, C $0,05 \%$, Cr 18,47\%, Ni $8,26 \%$, Mn 0,94\%, P 0,04\%, Si 0,29\%, Cu $0,15 \%$. Pirolisator terlihat pada gambar 1 . Dan spesifikasi Pirolisator seperti terlampir pada tabel 1.

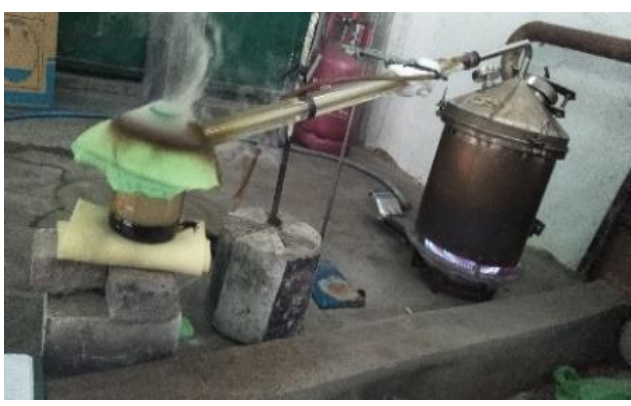

Gambar 1. Pirolisator

Tabel 1. Spesifikasi pirolisator

\begin{tabular}{ll}
\hline Deskripsi & Spesifikasi \\
\hline Tinggi & $405 \mathrm{~mm}$ \\
Diameter tabung & $300 \mathrm{~mm}$ \\
D input- output & $98 \mathrm{~mm}$ \\
Diameter pipa uap & $20 \mathrm{~mm}$ \\
Material & AISI 304, tebal 1,2 \\
Kapasitas & $\mathrm{mm}$ \\
\hline
\end{tabular}

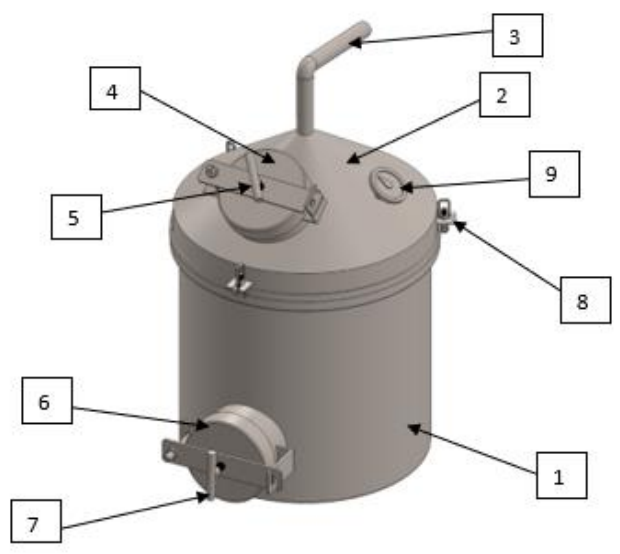

Gambar 2. Pemodelan Pirolisator 
Tabel 2. Nama bagian pirolisator

\begin{tabular}{|c|c|c|}
\hline No. & Nama bagian & Kegunaan \\
\hline 1 & Tabung utama & $\begin{array}{l}\text { Proses } \\
\text { pirolisis }\end{array}$ \\
\hline 2 & $\begin{array}{l}\text { Tutup tabung } \\
\text { utama }\end{array}$ & $\begin{array}{l}\text { Penutup } \\
\text { pirolisis }\end{array}$ \\
\hline 3 & Pipa uap & $\begin{array}{l}\text { Jalur } \\
\text { keluarnya uap }\end{array}$ \\
\hline 4 & $\begin{array}{l}\text { Lubang dan } \\
\text { tutup input }\end{array}$ & $\begin{array}{l}\text { Jalur } \\
\text { masuknya } \\
\text { material }\end{array}$ \\
\hline 5 & $\begin{array}{l}\text { Pengunci tutup } \\
\text { input }\end{array}$ & $\begin{array}{l}\text { kunci tutup } \\
\text { input }\end{array}$ \\
\hline 6 & $\begin{array}{l}\text { Lubang dan } \\
\text { tutup output }\end{array}$ & $\begin{array}{l}\text { Jalur } \\
\text { keluarnya } \\
\text { material }\end{array}$ \\
\hline 7 & $\begin{array}{l}\text { Pengunci tutup } \\
\text { output }\end{array}$ & $\begin{array}{l}\text { Kunci tutup } \\
\text { output }\end{array}$ \\
\hline 8 & Pengunci putar & Kunci tabung \\
\hline 9 & Termometer & $\begin{array}{l}\text { Pengontrol } \\
\text { temperatur }\end{array}$ \\
\hline
\end{tabular}

\section{Pemodelan dan Simulasi Pirolisator}

Tahapan proses simulasi dilakukan dengan cara pemasangan LID/ sumbatan, penentuan parameter, penentuan kondisi batas/ boundary condition sebagai masukan dalam proses simulasi pada pemodelan alat, seperti terlihat pada gambar 3 .

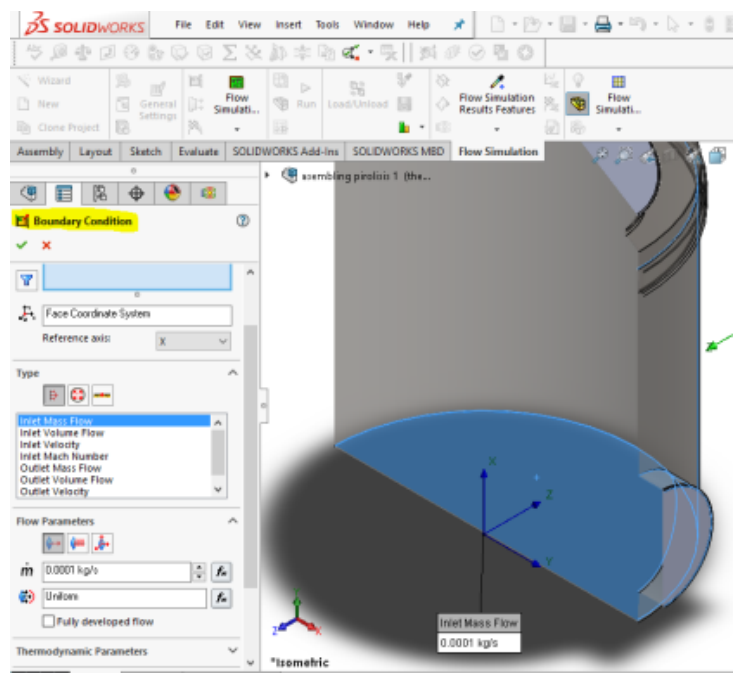

Gambar 3. penentuan boundary condition

Kemudian Penentuan goal, dan yang terakhir yaitu proses kalkulasi dan analisa hasil simulasi. Adapun hasil simulasi didapatkan apabila proses kalkulasi telah selesai, hasil yang didapatkan sesuai dengan parameter yang telah di masukan.

\section{HASIL DANPEMBAHASAN}

Hasi

Pada proses simulasi model, parameter sebagai acuan yakni dengan menggunakan data real dari hasil pengujian alat di laboratorium, data yang digunakan seperti tersaji pada tabel 3 .

\section{Tabel 3. Parameter Simulasi}

\begin{tabular}{ll}
\hline Deskripsi & Parameter \\
\hline $\begin{array}{l}\text { Material yang } \\
\text { digunakan }\end{array}$ & AISI 304, tebal 1,2 mm \\
$\begin{array}{l}\text { Suhu kompor } \\
\text { Tekanan }\end{array}$ & $\begin{array}{l}400{ }^{\circ} \mathrm{C} \text { (konstan) } \\
\text { atm. (konstan) }\end{array}$ \\
\hline
\end{tabular}

Parameter yang digunakan dalam simulasi yaitu dengan menggunakan suhu kompor 400 ${ }^{\circ} \mathrm{C}$ konstan sesuai pada saat pengujian alat, dan juga tekanan di dalam tabung pirolisator di asumsikan konstan 1 atm., hasil simulasi dapat diligat pada gambar 4 .

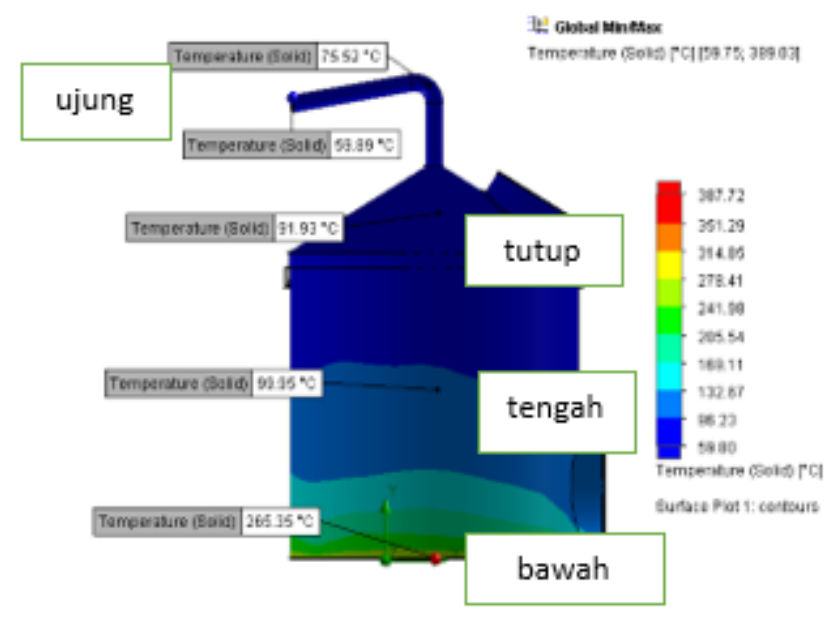

\section{Gambar 4. hasil simulasi dengan suhu kompor $400{ }^{\circ} \mathrm{C}$}

Hasil simulasi permodelan pirolisator dengan suhu kompor $400{ }^{\circ} \mathrm{C}$ dengan tekanan 1 atm. konstan seperti pada gambar 4, bahwa terjadi perubahan kontur warna yang berbeda pada permodelan, untuk sebaran temperatur yang tinggi ditandai dengan warna merah dan untuk temperatur yang rendah ditandai dengan warna biru tua, dari simulasi menghasilkan temperatur paling tinggi pada dasar tabung sebesar 265,35 ${ }^{\circ} \mathrm{C}$ karena merupakan posisi terdekat dengan sumber panas, dan temperatur terendah pada ujung pipa asap sebesar $59,89^{\circ} \mathrm{C}$ karena letaknya paling jauh dari sumber panas. 
Sedangkan pada hasil pengukuran temperatur pada saat pengujian menunjukkan temperatur tertinggi terletak pada dasar tabung sebesar 294 ${ }^{\circ} \mathrm{C}$ dan temperatur terendah terletak pada tengah tabung sebesar $52{ }^{\circ} \mathrm{C}$, hal ini disebabkan panas yang keluar terserap terlebih dahulu oleh bahan isian yang ada di dalam tabung pirolisator sehingga temperatur yang ada pada ujung pipa asap hanya $63{ }^{\circ} \mathrm{C}$. Pada penelitiannya Gabe (2015), mendapatkan hasil pada simulasi pemodelan reaktor pirolisator pada temperatur $400{ }^{\circ} \mathrm{C}$ didapatkan temperatur tertinggi sebesar $404{ }^{\circ} \mathrm{C}$ pada dasar reaktor dan temperatur terendah sebesar $64{ }^{\circ} \mathrm{C}$ pada outlet reaktor dengan 52,3 menit waktu pengujian.

Hasil pengukuran suhu real berbeda dengan suhu simulasi karena pada simulasi pemodelan hanya menggunakan uap air sebagai kondisi batas tidak ada beban atau tambahan material yang berada di dalam reaktor pirolisator, sedangkan pada hasil pengukuran real terdapat material di dalam pirolisator berupa tempurung kelapa kering, berdasar hasil yang didapat dengan simulasi maka rambatan panas yang terjadi di dalam tabung pirolisator merupakan perpindahan panas secara konveksi yaitu dari uap menuju dinding tabung.

Gambar 5 menunjukkan data hasil perbandingan dari pengukuran temperatur pada waktu pengujian alat dengan data hasil pengukuran pada waktu simulasi pemodelan alat.

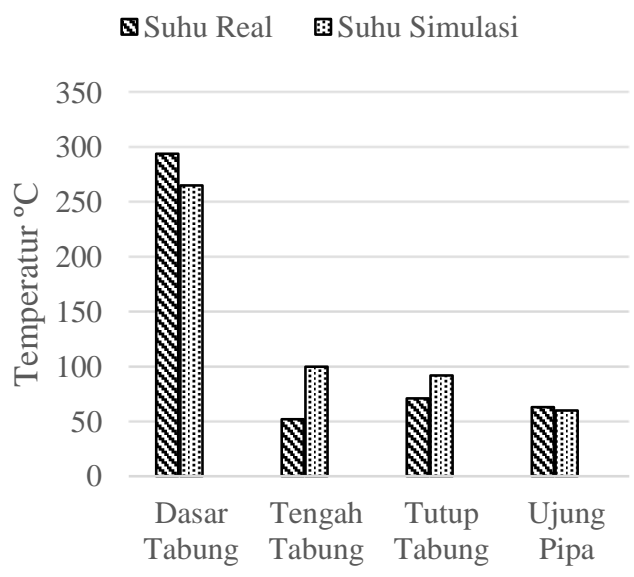

\section{Gambar 5. Perbandingan hasil real dengan simulasi.}

\section{Pembahasan}

Proses distribusi temperatur pada dinding reaktor dapat di analisa dengan memakai titik koordinat yang telah ditentukan untuk mencari perbandingan antara hasil simulasi dengan hasil analisa perhitungan seperti terlihat pada gambar 6 yang juga menampilkan adanya degradasi warna yang berbeda, perbedaan pada warna tersebut memiliki arti tersendiri yairu semakin panas permukaan model padda saat sesudah simulasi, maka warnanya akan semakin merah gelap, dan semakin rendah suhunya maka warnanya akan semakin biru gelap.

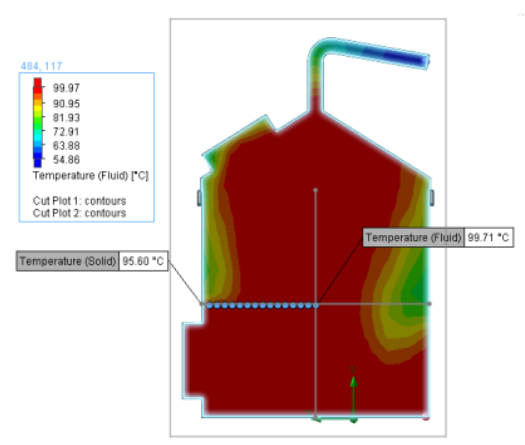

\section{Gambar 6. Titik koordinat distribusi temperatur $\mathrm{X}_{1}$}

Dari titik koordinat yang sudah ditentukan pada gambar 6 diketahui bahwa temperatur fluida di titik nol $\left(T \infty\right.$ ) adalah $99,71{ }^{\circ} \mathrm{C}$ dan temperatur pada dinding dalam (Tw) adalah $95,60{ }^{\circ} \mathrm{C}$, sehingga distribusi temperatur dapat dihitung dengan menggunakan persamaan (2) didapatkan hasil $98,23{ }^{\circ} \mathrm{C}$ pada titik koordinat (x-0.06; y-0.15; z-0.3). Hal ini berlaku juga dalam menghitung distribusi temperatur pada koordinat ( $\mathrm{x}-0.07$ sampai dengan $\mathrm{x}-0.20)$.

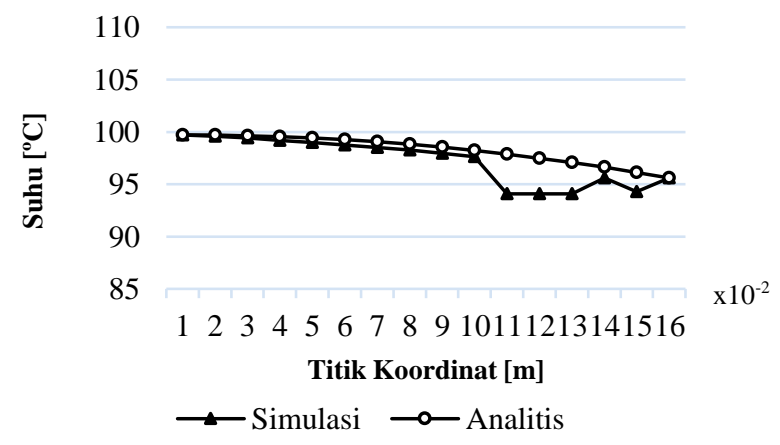

\section{Gambar 7. Perbandingan hasil simulasi dan analitis koordinat $\mathbf{X}_{1}$.}

Pada gambar 7 terlihat bahwa titik awal dimulai merupakan suhu fluida pada titik nol $(\mathrm{x}-0.05 ; \mathrm{y}-0.15 ; \mathrm{z}-0.3)$ dengan nilai $99.71{ }^{\circ} \mathrm{C}$ dan titik akhir berada pada koordinat $(\mathrm{x}-0.20$; $\mathrm{y}$ $0.15 ; \mathrm{z}-0.3)$ dengan nilai $95.60{ }^{\circ} \mathrm{C}$. Hal tersebut 
sebagai perhitungan menggunakan acuan suhu yang ada pada simulasi.

\section{KESIMPULAN}

1. Jenis rambatan panas yang terjadi pada reaktor pirolisator adalah konveksi pada bagian dinding samping dalam, walaupun ada dua kondisi yaitu konduksi terhadap logam sejenis pada dasar reaktor akan tetapi adanya fluida berupa uap yang mempunyai perubahan temperatur secara tidak langsung juga mempengaruhi adanya perpindahan kalor pada dinding dalam bagian samping reaktor pirolisator .

2. Proses terjadinya rambatan panas pada dinding reaktor pirolisator ditandai dengan adanya perbedaan kontur warna pada dinding reaktor selama simulasi berlangsung.

\section{DAFTAR PUSTAKA}

Demirbas A. (2009). Biorefineries: Current activities and future developments. Energy Conversion and Management. 50 (2009):2782-2801.

doi: 10.1016/j.enconman.2009.06.035.

Demirbas A. (2005). Pyrolysis of ground beech wood in irregular heating rate conditions. Journal of Analytical Applied and Pyrolysis. 73(1): 39-43. doi: 10.1016/j.jaap.2004.04.002.

Gabe, F. A., (2015). Analisa Termal Pada Rancang Bangun Reaktor Pirolisis Untuk Memproduksi Bahan Bakar Minyak Dari Limbah Plastik. Skripsi. Institut Pertanian Bogor, Bogor.

Holman, J. P, (1995). Heat Transfer, 6th Edition. Department of Mechanical Engineering Southern Methodist University (US). McGraw-Hill.

Kreith, F, (1994). Principles Of Heat Transfer, 3rd Edition. University Of Colorado.

Matsson J.E, (2013) An Introduction to SolidWorks Flow Simulation Text book. SDC Publications.

Paris O, Zollfrank C, Zickler GA. (2005). Decomposition and Carbonization of Wood Biopolymer Microstructural Study of Wood Pyrolysis. Carbon. 43(2005): 53-56. doi: 10.1016/j.carbon.2004.08.034. 